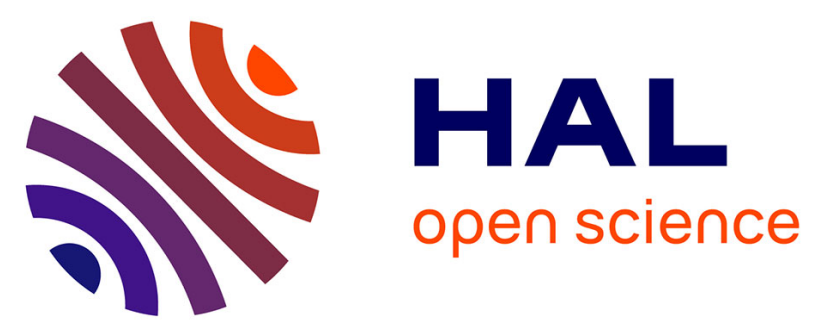

\title{
Long-term functional benefits of human embryonic stem cell-derived cardiac progenitors embedded into a fibrin scaffold
}

\author{
Valérie Bellamy, Valérie Vanneaux, Alain Bel, Hany Nemetalla, Solène \\ Emmanuelle Boitard, Yohan Farouz, Pierre Joanne, Marie-Cécile Perier, \\ Estelle Robidel, Chantal Mandet, et al.
}

\section{To cite this version:}

Valérie Bellamy, Valérie Vanneaux, Alain Bel, Hany Nemetalla, Solène Emmanuelle Boitard, et al.. Long-term functional benefits of human embryonic stem cell-derived cardiac progenitors embedded into a fibrin scaffold. The Journal of Heart and Lung Transplantation, 2014, 34 (9), pp.1198-1207. 10.1016/j.healun.2014.10.008 . hal-01103134

\section{HAL Id: hal-01103134 \\ https://hal.sorbonne-universite.fr/hal-01103134}

Submitted on 14 Jan 2015

HAL is a multi-disciplinary open access archive for the deposit and dissemination of scientific research documents, whether they are published or not. The documents may come from teaching and research institutions in France or abroad, or from public or private research centers.
L'archive ouverte pluridisciplinaire HAL, est destinée au dépôt et à la diffusion de documents scientifiques de niveau recherche, publiés ou non, émanant des établissements d'enseignement et de recherche français ou étrangers, des laboratoires publics ou privés. 
-1 -

\section{LONG TERM FUNCTIONAL BENEFITS OF HUMAN EMBRYONIC STEM CELL- DERIVED CARDIAC PROGENITORS EMBEDDED INTO A FIBRIN SCAFFOLD}

Valérie Bellamy ${ }^{\mathrm{a}}$, Valérie Vanneaux ${ }^{\mathrm{b}}$, Alain Bel ${ }^{\mathrm{a}, \mathrm{c}}$, Hany Nemetalla ${ }^{\mathrm{a}, \mathrm{d}}$, Solène Emmanuelle Boitard ${ }^{\mathrm{e}}$, Yohan Farouz ${ }^{\mathrm{a}}$, Pierre Joanne ${ }^{\mathrm{e}}$, Marie-Cécile Perier ${ }^{\mathrm{a}}$, Estelle Robidel ${ }^{\mathrm{a}}$, Chantal Mandet ${ }^{\mathrm{a}}$, Albert Hagège $^{\mathrm{a}, \mathrm{d}}$, Patrick Bruneval ${ }^{\mathrm{a}, \mathrm{f}}$, Jérôme Larghero ${ }^{\mathrm{b}}$, Onnik Agbulut $\mathrm{e}^{\mathrm{e}}$, Philippe Menasché $\mathrm{e}^{\mathrm{a}, \mathrm{c}^{*}}$ ${ }^{\mathrm{a}}$ INSERM U970, Hôpital Européen Georges Pompidou, Paris, France; ${ }^{\mathrm{b}}$ Assistance Publique-Hôpitaux de Paris, Hôpital Saint-Louis, Cell Therapy Unit and Clinical Investigation Center in Biotherapies (CBT501); Inserm UMR1160; Univ Sorbonne Paris Cité, Paris, France; 'Assistance PubliqueHôpitaux de Paris, Hôpital Européen Georges Pompidou, Department of Cardiovascular Surgery, Paris, France; ${ }^{\mathrm{d}}$ Assistance Publique-Hôpitaux de Paris, Hôpital Européen Georges Pompidou, Department of Cardiology, Paris, France; ' Sorbonne Universités, UPMC Univ Paris 06, IBPS, UMR CNRS 8256, Biological Adaptation and Ageing, Paris-France; ${ }^{\mathrm{f}}$ Assistance Publique-Hôpitaux de Paris, Hôpital Européen Georges Pompidou, Department of Pathology, Paris, France.

Short title. Long-term functional evaluation of cardiac progenitors in ischemic cardiomyopathy

*These authors contributed equally to this work

\section{Corresponding authors}

Philippe Menasché, Department of Cardiovascular Surgery, Hôpital Européen Georges Pompidou, 20, rue Leblanc, 75015 Paris-France. Phone: +33-1-56.09.36.22; philippe.menasche@egp.aphp.fr Onnik Agbulut, UMR CNRS 8256, University Pierre et Marie Curie, 7 quai St-Bernard, 75005 ParisFrance. Phone: +33-1-56.09.36.22; onnik.agbulut@upmc.fr 
$-2-$

\section{Abstract}

Background. Cardiac-committed cells and biomimetic scaffolds independently improve the therapeutic efficacy of stem cells. This study tested the long-term effects of their combination. Methods and Results. Eighty immune-deficient rats underwent permanent coronary artery ligation. Five to 7 weeks thereafter, those with an echocardiographically-measured ejection fraction (EF) $\leq 55 \%$ were reoperated on and randomly allocated to receive a cell-free fibrin patch $(n=25)$, a fibrin patch loaded with 700,000 human embryonic stem cell (ESC) pre-treated to promote early cardiac differentiation $\left(\mathrm{SSEA1}^{+}\right.$progenitors $\left.[\mathrm{n}=30]\right)$ or to serve as sham-operated animals $(\mathrm{n}=25)$. Left ventricular function was assessed by echocardiography at baseline and every month thereafter until 4 months. Hearts were then processed for the assessment of fibrosis and angiogenesis and a 5component heart failure score was constructed by integrating the absolute change in left ventricular end-systolic volume (LVESV) between 4 months and baseline, and the qPCR-based expression of natriuretic peptides $\mathrm{A}$ and $\mathrm{B}$, myosin heavy chain 7 and periostin. All data were recorded and analyzed blindly. The cell-treated group consistently yielded better functional outcomes than the sham-operated group ( $p=0.002$ for EF; $p=0.01$ for LVESV). Angiogenesis in the border zone was also significantly greater in the cell-fibrin group $(\mathrm{p}=0.006)$ which yielded the lowest heart failure score $(p=0.04$ vs sham). Engrafted progenitors were only detected shortly after transplantation; no grafted cells were identified after 4 months. There was no teratoma either.

Conclusion. A fibrin scaffold loaded with ESC-derived cardiac progenitors results in sustained improvement of contractility and attenuation of remodelling without sustained donor cell engraftment. A paracrine effect, possibly on innate reparative responses, is a possible mechanism for this enduring effect.

\section{Introduction}

At least, two important lessons can be drawn from the multiple cardiac stem cell therapy reported so far. The first is that regardless of whether the transplanted cells directly generate a new myocardial 


\section{$-3-$}

tissue or, more likely, act by harnessing endogenous repair pathways to induce host-derived regeneration, ${ }^{1}$ the most effective seem those committed to a cardiac lineage. ${ }^{2,3}$ In this setting, along with mesenchymal stem cells exposed to a cocktail of cardiopoietic factors prior to transplantation ${ }^{4}$ and cardiospheres, ${ }^{5}$ pluripotent stem cells are attractive because of their intrinsic capacity to be differentiated in any lineage, including the cardiomyogenic one, in response to appropriate cues. ${ }^{6}$ The second important lesson is that conventional needle-based intramyocardial injections have several limitations, including random distribution of cells, stress-induced cell damage ${ }^{7}$ and, possibly, induction of arrhythmias. ${ }^{8,9}$ Since cardiac surgery provides the unique opportunity of a direct control over the heart, several studies have assessed the effects of replacing multiple intramyocardial injections by the epicardial delivery of a cellularized patch and, overall, their results support the superiority of the latter approach with regard to cell survival, ${ }^{10-13}$ reduction of fibrosis, ${ }^{12-14}$ increase in angiogenesis $^{12-14}$ and improvement of function. ${ }^{10,}$ 12-15 Additional advantages of the patch-based approach include strengthening of the infarcted wall which may contribute to limit adverse remodelling ${ }^{16}$ and provision of a template for cells to proliferate and secrete their own matrix to which they can anchor. ${ }^{15}$ Among the diverse materials that can be used, fibrin is attractive because of its multiple advantages which include biocompatibility, suitability for cell adhesion, ${ }^{17}$ possibility to act as a reservoir for controlled-release growth factors ${ }^{18}$ and a long-standing safety record when used as an hemostatic sealant in surgery. ${ }^{19}$

The present study was therefore designed to leverage these data by combining the use of human embryonic stem cell (ESC)-derived cardiac progenitors with their incorporation into a fibrin scaffold and to assess the outcome of such a composite construct in a rat model of myocardial infarction subjected to a serial and extended (4 months) functional follow-up.

\section{Methods}

\section{Animals}




\section{$-4-$}

Eighty female Nude rats (Charles River) weighing an average of 200-250 g were used in this study. All procedures were approved by our institutional Ethics Committee and complied with the European legislation (European Commission Directive 86/609/EEC) on animal care.

\section{Experimental protocol}

Myocardial infarction was created as described previously ${ }^{14}$. Five to 7 weeks after myocardial infarction, rats underwent a baseline echocardiographic assessment of left ventricular (LV) function and all those with an ejection fraction $(\mathrm{EF}) \geq 55 \%$ were excluded. The remaining rats were reoperated on by a median sternotomy and randomly allocated to receive a cell-free fibrin patch $(n=25)$ or a fibrin patch loaded with 700,000 ESC-derived SSEA- $1^{+}$progenitors $(n=30)$. The patch was delivered onto the clearly visible akinetic area and secured to the epicardium by three $6 / 0$ polypropylene sutures. Twenty-five additional rats assigned to a sham group only underwent the open-chest placement of similar sutures, without any other procedure. No medical treatment for heart failure was given. Three additional rats receiving a progenitor cell-loaded fibrin patch were used for an early posttransplantation (1, 2 and 7 days) histological assessment.

\section{Preparation of the SSEA-1 ${ }^{+}$progenitors}

The progenitors were derived from the I6 ESC line (generously provided by J. Itskovitz and M. Amit, Technion Institute, Haïfa, Israël) according to a a relatively simple growth factor-based protocol attempting to recapitulate signalling events involved in embryonic cardiogenesis ${ }^{20-22}$ (detailed in the Supplementary Material online section). This protocol allowed to reproducibly generate a population of SSEA-1-positive early cardiac progenitors, primarily expressing Isl-1, a transcription factor for both the first and second heart fields ${ }^{23}$ but also additional genes characteristic of different developmental stages of cardiogenesis. ${ }^{24}$ The cardiomyocyte-oriented fate of this population has previously been confirmed in vivo in a nonhuman primate model of myocardial infarction. ${ }^{25}$

\section{Preparation of the fibrin patch}


$-5-$

Seven-hundred thousand SSEA-1-positive progenitors were first added to $150 \mu \mathrm{L}$ of a solution made of fibrinogen $(20 \mathrm{mg} / \mathrm{mL})$ and $\alpha$-MEM medium (Macopharma, Tourcoing, France) in an agarosecoated Petri dish. Four units of thrombin were then added as evenly distributed $25-\mu \mathrm{L}$ droplets of an equivalent volume of culture medium supplemented with thrombin to induce polymerization of the gel, which occurred in less than 10 minutes $\left(\right.$ at $37^{\circ} \mathrm{C}$ ). Both fibrinogen and thrombin were components of the Evicel ${ }^{\circledR}$ kit (Ethicon Biosurgery, Omrix Biopharmaceuticals-Ethicon Biosurgery, Rhode Saint Genèse, Belgium). Previous studies in the laboratory have shown that this fibrinogen-thrombin ratio is appropriate to generate mechanically robust patches with good handling and suturability characteristics and well-preserved cell viability.

\section{Assessment of left ventricular function}

Left ventricular function was assessed by echocardiography at baseline and every month thereafter until sacrifice at 4 months, as described previously ${ }^{14}$ (more details are available in the Supplementary Material online section).

\section{Histological and immunohistochemical analyses}

Four months following the sham or transplantation procedures, rats were euthanized and sacrificed. Explanted hearts were processed for the determination of fibrosis and angiogenesis. In separate experiments, tracking of cell fate was performed one day and one week after transplantation using immunostaining against lamin A/C (all procedures detailed in the Supplementary Material online section) and completed, at 4 months only, by the search for human-specific Alu sequences by RTPCR.

\section{Relative quantification of gene expression by real-time PCR}

Total RNA was extracted from heart tissue samples using TRIzol ${ }^{\circ}$ lysis reagent (Life Technologies, Saint-Aubin, France) and TissueLyser II system (Qiagen France SAS, Courtaboeuf, France) following the manufacturers' instructions. Real-time PCR was performed using LightCycler 480® (Roche Diagnostics, France) as described in the Supplementary Material online section.

\section{Assessment of a heart failure index}


$-6-$

In 20 randomly selected hearts $(n=7,7$ and 6 for sham-operated, control acellular fibrin patches and cell-treated patches, respectively), a whole set of functional and PCR data were available. This cohort was therefore used for generating a 5-component heart failure score including the absolute change in LV end-systolic volume (ESV) between 4 months and baseline, and the qPCR-based expression of natriuretic peptides $\mathrm{A}$ and $\mathrm{B}$, myosin heavy chain 7 and periostin.

\section{Statistics}

Data are summarized using mean (IC95\%) or mean (SEM) values. Survival between groups was compared using the log-rank test and Kaplan Meier curves were plotted. Within each group, LV function variables measured at baseline and at 4 months were compared using paired Student tests. Across groups, the changes of LV function variables between repeated assessment (baseline, 1, 2, 3 and 4 months) were compared using a linear mixed model analysis. The mean percentages of fibrosis and angiogenesis were compared between groups using analysis of variance. Pairwise comparisons were done and $p$-values were adjusted for multiple testing (Tukey adjustment). The "heart failure index" was constructed by standardizing the 5 components on the overall population (= computing zscore for each variable) and then averaged them. Comparisons of this index between groups were made using analysis of variance (Tukey adjustment for multiple testing). For all analyses, a two-tailed $p$-value $<0.05$ was considered statistically significant.

Analyses were conducted using SAS 9.4 (Statistical Analysis System, Cary, NC, USA).

\section{RESULTS}

\section{Characteristics of the transplanted SSEA1 ${ }^{+}$cell population.}

Following immunomagnetic sorting, the purity rate of the SSEA-1-positive cell population was $92.5 \%$ $\pm 2.6 \%$. The transcriptomic profiling of this population, as assessed by Affymetrix microarray analysis, showed the down-regulation of pluripotency-associated genes like SOX2, SOX21, NANOG, HESX1, LEFTY, ZIC3 (Figure 1A), as compared with undifferentiated I6 ESC and this pattern was mirrored by the upregulation of cardiac mesoderm-committed genes like HAND1, ISL1, EOMES, 
HAPLN1, BMP4, PKP2 (Figure 1B). Based on that same transcriptomic analysis, the SSEA-1negative cell fraction was also characterized by a switch-off of most pluripotency genes (Figure 1A).

Four hours after sorting, a time point selected to match the timing by which the patch would be effectively delivered onto the heart, less than $10 \%$ of the SSEA-1-positive scaffold-embedded cells were found apoptotic, as shown by TUNEL staining and caspase-3 expression (data not shown), while markers suggestive of a cardiomyogenic lineage like Isl-1 were identified (Figure 2, upper panel). Moreover, the ability of the SSEA-1-positive cells to keep proliferating into the fibrin scaffold was demonstrated by Ki67 staining (Figure 2, lower panel).

\section{Left ventricular function assessment.}

After exclusion of rats with preserved LV functions (LVEF $\geq 55 \%$ ), baseline LVEF did not differ between the three groups: $47.46 \%$ [95\%CI:45.28\%;49.63\%], 47.68\% [45.96\%;49.40\%], and $47.37 \%$ [44.97\%;49.77\%], in sham-operated $(n=18)$, control $(n=19)$ and treated $(n=20)$ hearts, respectively . Over the 4-month follow-up period, the death rate did not significantly differ among the three groups (12, 13 and 14 deaths in the sham, control and treated groups, respectively; Figure 3A) which let a total of 41 surviving animals (13 sham-operated rats, 12 controls and 16 treated rats) meeting the preset inclusion criterion (LVEF $\leq 55 \%)$ available for the last 4-month echocardiographic assessment.

Over this 4-month follow-up period, the patterns of changes remained fairly consistent within each group (Figure 3B). Function remained stable in the sham group in which the LVEF, at 4 months, was $48.45 \%(44.71 \% ; 52.18 \%)$; it slightly increased in the control acellular fibrin group $(50.36 \%$ [47.29\%;53.42\%]) and to a still greater extent in the cell-treated group $(53.19 \%[50.10 \% ; 56.29 \%]$, $p=0.002$ vs sham). When data were expressed as the absolute difference between the baseline value and the 4-month final study point, LVEF was found to have increased by $0.09 \% \pm 0.99 \%$ (mean \pm SEM) in sham-operated hearts, $2.36 \% \pm 0.80 \%$ in control cell-free fibrin-treated hearts ( $p=0.014$ vs baseline), and $5.68 \% \pm 1.29 \%$ in cell + fibrin-treated hearts ( $p=0.0005$ vs baseline).

Left ventricular end-diastolic volumes (LVEDV) were likewise similar at baseline between the three groups: $\quad 344.81 \mu \mathrm{L} \quad(95 \% \mathrm{CI}: 319.38 ; 370.23), \quad 365.12 \mu \mathrm{L} \quad(328.88 ; 401.35), \quad 357.63 \mu \mathrm{L}$ 
$-8-$

(95\%CI:323.89;391.37) in sham, control and treated hearts, respectively. However, the patterns of changes were then markedly different (Figure 3C). Volumes steadily increased to a similar extent in the sham and control groups (absolute difference between 4 months and baseline: $44.68 \mu \mathrm{L} \pm 20.83 \mu \mathrm{L}$; $p=0.053$ and $50.27 \mu \mathrm{L} \pm 25.95 \mu \mathrm{L}, p=0.07$ respectively) whereas the $\mathrm{LV}$ dilatation was much less pronounced in the treated group (absolute difference between 4 months and baseline: $4.64 \mu \mathrm{L} \pm 24.07$ $\mu \mathrm{L}, p=0.85$ ). Patterns of changes in LV end-systolic volumes (LVESV) still more clearly delineated between-group differences (Figure 3D) as they increased in the sham and control groups (absolute difference between 4-month and baseline values: $28.08 \mu \mathrm{L} \pm 14.65 \mu \mathrm{L}$ and $15.41 \mu \mathrm{L} \pm 13.36 \mu \mathrm{L}$, respectively), whereas they decreased by $16.76 \mu \mathrm{L} \pm 15.55 \mu \mathrm{L}$ in hearts receiving the cell-loaded fibrin patch ( $p=0.013$ vs sham; $p=0.052$ vs controls).

The functional efficacy of epicardially delivered SSEA-1-positive progenitors was partially supported by real-time PCR analysis, which demonstrated a reduced expression of the stress-induced betamyosin heavy chain genes, atrial natriuretic factor, brain natriuretic peptide and periostin in the treated group as compared to sham (data not shown). When these PCR data were combined with LVESV changes to generate a 5-component heart failure index (Figure 4), the highest score was seen in the sham-operated group $(2.24 \pm 1.29)$. It was lower in control hearts $(-0.74 \pm 0.84)$ and further decreased in the treated group $(-1.75 \pm 0.84, p=0.04$ vs sham $)$.

\section{Histological and immunohistochemical analyses.}

The extent of fibrosis did not significantly differ between the three groups (Figure 5A). Conversely, angiogenesis in the border zone was significantly greater in the cell+fibrin group ( $p=0.006$ vs sham, Figure 5B). At the 4-month time point, there was no teratoma in 6 hearts treated with the cell-loaded fibrin patch which were specifically examined for this complication. Lamin A/C-positive human cells were detected by immunostaining one day after transplantation in the patch implantation area (Supplemental Figure 1) but could no longer be found after one week. Based on this result, we reasoned that the probability for cells to persist at 4 months was extremely small and therefore used PCR rather than immunostaining to sensitize their tracking in 6 cells+fibrin-treated hearts, taking 7 sham-operated hearts and 7 acellular fibrin patch-grafted hearts as controls. Three primers were used 


\section{-9 -}

for probing different regions of the human-specific Alu DNAsequence but, as expected, there was no detectable signal with either primer at this late time point in any heart tissue sample (comprising both the area of patch implantation and the nongrafted underlying myocardium).

\section{DISCUSSION}

The major finding of the present study is that a fibrin patch, in which ESC-derived cardiac progenitors have been embedded, improves pump function and limits adverse ventricular remodelling in a rat model of myocardial infarction and that, given the life expectancy of rats, these effects seem to be sustained over a reasonably long period of time.

\section{Cell scaffolding.}

. After having tested several materials, including scaffold-free cell sheets, ${ }^{14,15,26}$ we selected fibrin as the cell matrix. In addition to its multiple above mentioned advantages, fibrin is attractive because of the tunability of its mechanical properties through an adjustment of the fibrinogen to thrombin ratio. Thus, in the present experiments, the selected ratio $(20 \mathrm{mg} / \mathrm{mL}$ and 4 Units $/ \mathrm{mL}$, respectively) allowed to achieve both an elasticity modulus (in the range of $6 \mathrm{kPa}$ ) matching that reported appropriate for cells of the mesodermal lineage ${ }^{27}$ and a fiber network density allowing ingrowth of host-derived vessels (Figure 5). The choice of transplanting 700,000 progenitor cells was based on preliminary screening experiments but we acknowledge that upscaling this number might have increased cell engraftment, at least early after patch delivery, as suggested by our observation of numerous donor cells inside the scaffold in a separate experiment where it was loaded with two million cells (Figure 6).This observation matches the finding that fibrin can increase the amount of cells retained into the myocardium 24 hours after an intramyocardial injection. ${ }^{28}$

\section{Interpretation of outcomes.}

The present results demonstrate that hearts receiving the cell-free fibrin patch tended to have slightly better functional outcomes than the sham-operated animals, which has been previously reported with the use of injected fibrin alone ${ }^{29}$ and which likely reflects an angiogenic effect. ${ }^{30,}{ }^{31}$ However, embedding SSEA- $1^{+}$cells in the fibrin matrix further improved contractile function and stabilization 
of remodelling as cells+fibrin-treated hearts consistently yielded higher values of LVEF (the increase of which between 4 months and baseline was more than two-fold higher than in the acellular fibrin group) but more importantly lower values of LVEDV and LVESV compared with their cell-free counterparts. Although focus on EF could suggest that LV function was only moderately impaired at baseline (after infarction), analysis of LV volumes at the same time point shows that they were dramatically enlarged compared with healthy hearts, ${ }^{32,33}$ which makes the 4-month attenuation of remodelling yielded by the cells+fibrin patch functionally relevant, particularly if one keeps in mind that LVESV has been reported to be a strong predictive factor of outcome in patients following a myocardial infarction. ${ }^{34}$ In keeping with these data, the cell-scaffold product also achieved the lowest value of the heart failure index generated by combining genomic and functional end points associated with heart failure, ${ }^{35}$ cardiomyopathy ${ }^{36}$ and adverse LV remodelling. ${ }^{37}$ Overall, these results are consistent with those previously reported with the use of fibrin used either in an injectable form mixed with skeletal myoblasts ${ }^{38}$ or bone marrow-derived cells ${ }^{28,39}$ or as an epicardial patch loaded with mouse ESC-derived BMP-2-treated cardiac progenitors ${ }^{40}$ or human $\mathrm{hESC}$-derived vascular cells ${ }^{41}$ in rat and porcine myocardial infarct models, respectively. Compared with the latter two studies, the present one differs by (1) the phenotype of the cells (in Vallée's study, ${ }^{40}$ ESC-derived cardiac progenitors were of mouse origin while in Xiong's study, ${ }^{41}$ the derivatives of the human ESC were not cardiomyocytes), (2) the extension of follow-up to 4 months (versus 50 days and 4 weeks in Vallée's and Xiong's studies, respectively), and (3) the fact that the tested cell-scaffold construct was manufactured, processed and quality-controlled under similar conditions as those used for the product planned for a human use. It is even possible that the beneficial effects of the fibrin material could have been optimized by seeding cells at the surface of the fibrin biomatrix instead of incorporating them into it. ${ }^{42}$

The mechanism of the incremental benefit afforded by the cell-loaded fibrin patch remains to be investigated. A de novo muscularization of the infarct tissue by the grafted cells can be excluded. In the present study, two methods were used for tracking donor cell fate: lamin $\mathrm{A} / \mathrm{C}$ protein expression and human Alu gene expression. As early as one week after patch implantation, lamin A/C-positive 


\section{$-11-$}

cells could no longer be detected and, expectedly, were not identified either after 4 months despite the use of a highly sensitive PCR-based tracking method. ${ }^{43}$ With the caveat of a shorter follow-up, a higher survival rate has been reported with the use of a fibrin patch loaded with human hESC-derived vascular cells, ${ }^{41}$ which might be related to differences in cell phenotype, processing, or timing of delivery. Whatsoever, the contrast, in the present experiments, between the absence of a long-term cell engraftment and a sustained functional benefit, similar to what has been reported with other cell types,${ }^{44}$ strongly supports a cell-induced paracrine signalling initiating a cascade of self-sustained events. This would be consistent with an attenuation of fibrosis and the increase in angiogenesis seen in the treated group. Our failure to identify cells expressing both markers of proliferation (Ki67) and cardiac lineage (troponin I) does not necessarily rule out an additional increase in the contractile cell pool (by mobilization of endogenous stem/progenitors or new divisions of mature cardiomyocytes) which could have been missed because of the late postprocedural sampling time ( 4 months). This paracrine hypothesis is relevant to the patch-based delivery strategy as shown by the ability of a cardiomyocyte-containing alginate scaffold to improve postinfarction heart function even though the grafted cells remain insulated from the host myocardium and cannot therefore couple with them. ${ }^{45}$ Reliance on paracrine effects has practical implications in that it leads to focus on the enhancement of early retention of grafted cells (rather than on their sustained survival), within a time frame matching the release of cell-derived biomolecules which could then paracrinally foster innate repair pathways before clearance of the donor cells.$^{44}$ We acknowledge that we did not dissect out the molecular events underpinning the postulated paracrine activation of endogenous reparative responses. Indeed, an increasing role is attributed to exosomes as possible mediators of the cells' paracrine effects ${ }^{46,47}$ and deciphering the nature of their content, particularly the miRNA profile, should help in mechanistically identifying the various pathways targeted by the cell-released biomolecules while providing clues for developing cell mimetics more suitable for large-scale clinical applications.

An important observation was the lack of teratoma in the immunodeficient rats after 4 months. This likely reflects the efficiency of the selection procedure aimed at discarding the cells unresponsive to the cardioinstructive cues. In this study, the population of progenitors was purified by 


\section{$-12-$}

immunomagnetic sorting against SSEA-1 (also called Sialyl-Lewis ${ }^{\mathrm{X}}$ ), a carbohydrate moiety expressed early during the differentiation of pluripotent $\mathrm{ESC}^{48}$ which is consistent with the fact that cell surface proteins incur changes in their glycosylation patterns when they transition from pluripotency to differentiation. The transcriptomic analysis of the purified SSEA-1-positive population has confirmed the down-regulation of pluripotency genes (primarily $N A N O G$ and $S O X-2$ ) which may still be expressed at various degrees in the residual contaminating SSEA-1-negative cells but probably not to the extent that a teratoma can develop since injection of this sole fraction in immunodeficient mice still failed to induce teratoma formation. ${ }^{24}$ The disappearance of the cells over time may also be considered as an additional flail-safe mechanism.

\section{Limitations.}

We acknowledge several limitations of this study. First, the follow-up was not extended beyond 4 months. However, such a duration is yet significant given the rat's life expectancy and the stability of functional data, as evidenced by the serial echocardiograms, provides an encouraging signal regarding the maintenance of the functional benefits over time. A second limitation is that cells may not migrate into the myocardium. This would be an issue if the grafted cells were supposed to generate a de novo myocardial tissue but, indeed, is not if they act primarily by releasing a blend of factors which can be released from the patch towards the underlying myocardium to harness endogenous repair pathways. Third, we did not document the potential occurrence of arrhythmic events. However, (i) the survival rate of the treated rats was not different from that of sham-operated animals and although we were not able to determine the causes of death in each group, this indirectly argues against a substantially greater occurrence of cell-induced life-threatening arrhythmias, and (ii) patches have been reported to be less arrhythmogenic than injections.. 9 Fourth, our "customized" heart failure score should be interpreted cautiously because it has not been externally validated and was constructed as a post-hoc composite of variables; of note, however, this index was not designed to predict survival, like the heart failure scores commonly used in the clinics, ${ }^{49}$ but rather to assess whether the combination of end points generated by different methods (echocardiography and genomics) but all relevant to heart dysfunction, would confirm the benefits of the cells+scaffold approach, which actually turned out to 


\section{$-13-$}

be the case. Finally, no mechanistic study was done to specifically determine the causes of cell loss which might have been facilitated by two model-intrinsic feature : (1) an immune response related to the xenogenic setting of the transplantation and which cannot be excluded, even in the nude rat, and (2) the stress that human cells have to withstand when they are implanted in a fast-beating rodent heart..

In conclusion, the present data support the functional efficacy of fibrin scaffolds harbouring ESCderived cardiac progenitors and provide additional evidence that a long-term cell engraftment may not be a prerequisite for a sustained benefit. As such, they may serve as a platform for the further development of cell-, cell-mimetics- or biomaterial-based strategies aimed at fostering endogenous reparative responses.

\section{CONFLICT OF INTEREST}

None of the Authors has a conflict of interest to disclose.

\section{FUNDINGS}

This work was supported by public funds from INSERM, University Paris Descartes and the LabEx REVIVE; and by charity funds from the Fondation de France, the Fondation Coeur et Artères, the Fondation de l'Avenir (ET2-658) and the Association Française contre les Myopathies, ANR-12RPIB-0015. P.J. was supported by a fellowship from the Fondation Lefoulon-Delalande and S.B. from the Conseil Régional d'Ile de France (DIM Biothérapies). 


\section{REFERENCES}

1- Garbern JC, Lee RT. Cardiac stem cell therapy and the promise of heart regeneration. Cell Stem Cell 2013;12:689-98.

2- Crisostomo PR, Abarbanell AM, Wang M, Lahm T, Wang Y, Meldrum DR. Embryonic stem cells attenuate myocardial dysfunction and inflammation after surgical global ischemia via paracrine actions. Am J Physiol Heart Circ Physiol 2008;295:H1726-35

3- Li TS, Cheng K, Malliaras K, et al. Direct comparison of different stem cell types and subpopulations reveals superior paracrine potency and myocardial repair efficacy with cardiosphere-derived cells. J Am Coll Cardiol. 2012;59:942-53.

4- Bartunek J, Behfar A, Dolatabadi D, et al. Cardiopoietic stem cell therapy in heart failure: the C-CURE (Cardiopoietic stem Cell therapy in heart failURE) multicenter randomized trial with lineage-specified biologics. J Am Coll Cardiol 2013;61:2329-38.

5- Malliaras K, Makkar RR, Smith RR, et al. Intracoronary cardiosphere-derived cells after myocardial infarction: evidence of therapeutic regeneration in the final 1-year results of the CADUCEUS trial (CArdiosphere-Derived aUtologous stem CElls to reverse ventricUlar dySfunction). J Am Coll Cardiol 2014;63:110-22.

6- Pal R. Embryonic stem (ES) cell-derived cardiomyocytes: a good candidate for cell therapy applications. Cell Biol Int 2009;33:325-36.

7- Aguado BA, Mulyasasmita W, Su J, Lampe KJ, Heilshorn SC. Improving viability of stem cells during syringe needle flow through the design of hydrogel cell carriers. Tissue Eng Part A 2012;18:806-15. 
$-15-$

8- Fukushima S, Varela-Carver A, Coppen SR, et al. Direct intramyocardial but not intracoronary injection of bone marrow cells induces ventricular arrhythmias in a rat chronic ischemic heart failure model. Circulation 2007;115:2254-61.

9- Terajima Y, Shimizu T, Tsuruyama S, et al. Autologous skeletal myoblast sheet therapy for porcine myocardial infarction without increasing risk of arrhythmia. Cell Medicine 2014;6:99109.

10- Sekine H, Shimizu T, Dobashi I, et al. Cardiac cell sheet transplantation improves damaged heart function via superior cell survival in comparison with dissociated cell injection. Tissue Eng Part A. 2011;17:2973-80.

11- Le Visage C, Gournay O, Benguirat N, et al. Mesenchymal stem cell delivery into rat infarcted myocardium using a porous polysaccharide-based scaffold: a quantitative comparison with endocardial injection. Tissue Eng Part A. 2012;18 :35-44.

12- Sekiya N, Tobita K, Beckman S, et al. Muscle-derived stem cell sheets support pump function and prevent cardiac arrhythmias in a model of chronic myocardial infarction. Mol Ther. 2013;21:662-9.

13- Araña M, Gavira JJ, Peña E, et al. Epicardial delivery of collagen patches with adiposederived stem cells in rat and minipig models of chronic myocardial infarction. Biomaterials.2014;35:143-51.

14- Hamdi H, Furuta A, Bellamy V, et al. Cell delivery : Intramyocardial injections or epicardial deposition ? A head-to-head comparison. Ann Thorac Surg 2009;87:1196-203.

15- Hamdi H, Planat-Benard V, Bel A, et al. Epicardial adipose stem cell sheets results in greater post-infarction survival than intramyocardial injections. Cardiovasc Res 2011;91:483-491.

16- Gaballa MA, Sunkomat JN, Thai H, Morkin E, Ewy G, Goldman S. Grafting an acellular 3dimensional collagen scaffold onto a non-transmural infarcted myocardium induces neoangiogenesis and reduces cardiac remodeling. J Heart Lung Transplant 2006;25:946-54. 
$-16-$

17- Barsotti MC, Felice F, Balbarini A, Di Stefano R. Fibrin as a scaffold for cardiac tissue engineering. Biotechnol Appl Biochem 2011;58:301-10.

18- Rajangam T, An SS. Fibrinogen and fibrin based micro and nano scaffolds incorporated with drugs, proteins, cells and genes for therapeutic biomedical applications. Int J Nanomedicine $2013 ; 8: 3641-62$

19- Rousou JA. Use of fibrin sealants in cardiovascular surgery: a systematic review. J Card Surg 2013;28:238-47.

20- Leschik J, Stefanovic S, Brinon B, Pucéat M. Cardiac commitment of primate embryonic stem cells. Nat Protoc 2008;3:1381-7.

21-Verma V, Purnamawati K, Manasi, Shim W. Steering signal transduction pathway towards cardiac lineage from human pluripotent stem cells: a review. Cell Signal 2013;25:1096-107.

22- Vallier L, Alexander M, Pedersen RA. Activin/Nodal and FGF pathways cooperate to maintain pluripotency of human embryonic stem cells. J Cell Sci 2005;118:4495-509.

23-Moretti A, Caron L, Nakano A, et al. Multipotent embryonic isl1+ progenitor cells lead to cardiac, smooth muscle, and endothelial cell diversification. Cell 2006;127:1151-65.

24- Menasché P, Vanneaux V, Fabreguettes JR, et al. Towards a clinical use of human embryonic stem cell-derived cardiac progenitors: a translational experience. Eur Heart $\mathrm{J}$ 2014;doi:10.1093/eurheartj/ehu192 (on-line).

25- Blin G, Nury D, Stefanovic S, et al. A purified population of multipotent cardiovascular progenitors derived from primate pluripotent stem cells engrafts in post-myocardial infarcted non-human primates. J Clin Invest 2010;120:1125-39.

26- Hamdi H, Boitard, S, Planat-Benard V, et al. Efficacy of Epicardially-delivered Adipose Stroma Cell Sheets in Dilated Cardiomyopathy. Cardiovasc Res 2013;99:640-7.

27- Jacot JG, McCulloch AD, Omens JH. Substrate stiffness affects the functional maturation of neonatal rat ventricular myocytes. Biophys J 2008;95:3479-87. 


\section{$-17-$}

28- Nakamuta JS, Danoviz ME, Marques FL, et al. Cell therapy attenuates cardiac dysfunction post myocardial infarction: effect of timing, routes of injection and a fibrin scaffold. PLoS One 2009;4:e6005.

29- Christman KL, Fok HH, Sievers RE, Fang Q, Lee RJ. Fibrin glue alone and skeletal myoblasts in a fibrin scaffold preserve cardiac function after myocardial infarction. Tissue Eng 2004;10:403-9.

30- Liu J, Hu Q, Wang Z, et al. Autologous stem cell transplantation for myocardial repair. Am J Physiol Heart Circ Physiol 2004;287:H501-11.

31-Ye L, Zhang P, Duval S, Su L, Xiong Q, Zhang J. Thymosin $\beta 4$ increases the potency of transplanted mesenchymal stem cells for myocardial repair. Circulation 2013;128:S32-41.

32- Kang KT, Coggins M, Xiao C, Rosenzweig A, Bischoff J. Human vasculogenic cells form functional blood vessels and mitigate adverse remodeling after ischemia reperfusion injury in rats. Angiogenesis 2013;16:773-84.

33- Sabatini CF, O'Sullivan ML, Valcour JE, Sears W, Johnson RJ. Effects of injectable anesthetic combinations on left ventricular function and cardiac morphology in Sprague-Dawley rats. J Am Assoc Lab Anim Sci. 2013;52:34-43.

34- Norris RM, White HD, Cross DB, Wild CJ, Whitlock RM. Prognosis after recovery from myocardial infarction: the relative importance of cardiac dilatation and coronary stenoses. Eur Heart J. 1992;13:1611-8.

35- Tan FL, Moravec C, Li J, et al. The gene expression fingerprint of human heart failure. PNAS 2002;99:11387-92.

36-Gibbons GH, Liew CC, Goodarzi MO et al. Genetic markers progress and potential for cardiovascular disease. Circulation 2004;109:IV-47-IV-58. 
$-18-$

37- Stansfield WE, Andersen NM, Tang RH, PhD, Selzman CH. Periostin is a novel factor in cardiac remodeling after experimental and clinical unloading of the failing heart. Ann Thorac Surg. 2009;88:1916-21.

38- Christman KL, Vardanian AJ, Fang Q, Sievers RE, Fok HH, Lee RJ. Injectable fibrin scaffold improves cell transplant survival, reduces infarct expansion, and induces neovasculature formation in ischemic myocardium. J Am Coll Cardiol 2004;44:654-60.

39- Ryu JH, Kim IK, Cho SW, et al. Implantation of bone marrow mononuclear cells using injectable fibrin matrix enhances neovascularization in infarcted myocardium. Biomaterials 2005;26:319-26.

40-Vallée JP, Hauwel M, Lepetit-Coiffé M, et al. Embryonic stem cell-based cardiopatches improve cardiac function in infarcted rats. Stem Cells Transl Med 2012;1:248-60.

41-Xiong Q, Hill KL, Li Q, et al. A fibrin patch-based enhanced delivery of human embryonic stem cell-derived vascular cell transplantation in a porcine model of postinfarction left ventricular remodeling. Stem Cells 2011;29:367-75.

42- Gerard C, Forest MA, Beauregard G, Skuk D, Tremblay JP. Fibrin gel improves the survival of transplanted myoblasts. Cell Transplant 2012;21:127-37.

43-Schneider T, Osl F, Friess T, Stockinger H, Scheuer WV. Quantification of human Alu sequences by real-time PCR - an improved method to measure therapeutic efficacy of antimetastatic drugs in human xenotransplants. Clinical \& Experimental Metastasis 2002;19:571582.

44- Levit RD, Landázuri N, Phelps EA, et al. Cellular encapsulation enhances cardiac repair. J Am Heart Assoc 2013;2:e000367.

45- Wendel JS, Ye L, Zhang P, Tranquillo RT, Zhang JJ. Functional consequences of a tissueengineered myocardial patch for cardiac repair in a rat infarct model. Tissue Eng Part A 2014;20:1325-35. 
$-19-$

46- Chen L, Wang Y, Pan Y, et al. Cardiac progenitor-derived exosomes protect ischemic myocardium from acute ischemia/reperfusion injury. Biochem Biophys Res Commun. 2013;431:566-71.

47- Ibrahim AGE, Cheng K, Marban E. Exosomes as critical agents of cardiac regeneration triggered by cell therapy. Stem Cell Reports 2014;2:606-19.

48- Mummery CL, Zhang J, Ng ES, Elliott DA, Elefanty AG, Kamp TJ. Differentiation of human embryonic stem cells and induced pluripotent stem cells to cardiomyocytes: a methods overview. Circ Res 2012;111:344-58.

49- Levy WC, Mozaffarian D, Linker DT, et al. The Seattle Heart Failure Model: prediction of survival in heart failure. Circulation. 2006;113:1424-33.

\section{Figures Legends}

Figure 1. In vitro characterization of human embryonic stem cells (ESC)-derived SSEA-1positive progenitors. Expression level of selected pluripotency-associated (A) and cardiac lineage commitment-associated (B) genes, as assessed by a transcriptome analysis using Affymetrix microarrays, in SSEA-1-positive progenitors, SSEA-1-negative cells and undifferentiated pluripotent I6 ESC taken as the reference $(100 \%)$. Data are reported as means \pm SEM. Heatmaps of the transcriptome have been previously published. ${ }^{24}$

Figure 2. Immunolabeling of SSEA-1-positive progenitors in the fibrin patch. The upper panel shows that the fibrin-embedded SSEA-1-positive progenitors express the cardiac transcription factor Isl-1 (green fluorescence) and the proliferation-associated protein Ki67 (green fluorescence, lower 
$-20-$

panel). Combined red and green fluorescence and DAPI-stained nuclei (blue) are shown in merged images. Note SSEA-1-positive progenitors co-stain with either Isl-1 or Ki67. Bar: $20 \mu \mathrm{m}$.

Figure 3. Four-month follow-up of SSEA-1-positive progenitor-grafted hearts in comparison with sham and control groups. (A) Kaplan-Meier survival curves during the 4-month follow-up. Percentages of surviving animals, in sham ( $\mathrm{n}=13$ out of 25$)$, control $(\mathrm{n}=12$ out of 25$)$ and treated $(\mathrm{n}=16$ out of 30) groups. No significant difference was observed in the survival rate between the different groups. Significance was analyzed with the log-rank test. (B) Changes in left ventricular ejection fraction (LVEF) over the 4-month follow-up period. Values are presented as percentages. * $p=0.014$ vs baseline; ** $p=0.0005$ vs baseline; $p=0.002$ vs sham. (C) Absolute changes in left ventricular enddiastolic volume (LVEDV) over the 4-month follow-up period; * $p=0.053$ vs baseline. (D) Absolute changes in left ventricular end-systolic volume (LVESV) over the 4-month follow-up period; * $p=0.013$ vs sham; $p=0.052$ vs controls. Data are reported as means \pm SEM.

Figure 4. Box-blot representation of the heart failure index. The absolute change in LVESV between 4 months and baseline and the qPCR-based expression of natriuretic peptides A and B, myosin heavy chain 7 and periostin were used to construct a 5-component heart failure index. The score yielded by the control and treated groups was calculated relative to that of the total 20-heart cohort. The boxes represent the lower to upper quartile range, the error bars represent the entire range, the horizontal bar represents the median value and dot points represent mean values. Note the significantly lower heart failure index in the treated group vs sham.

Figure 5. Box-blot representation of fibrosis (A) and number of capillaries (B) in sham, control and treated hearts. Four months after treatment, 6-10 sections per heart were stained by Sirius red (fibrosis) or immunostained with a rat-specific endothelial cell antibody (to label capillaries; 7 sections per heart). The area of fibrosis and number of capillaries were quantified using Metamorph software (Universal Imaging Corporation, USA). Fibrosis was expressed as the ratio between the area of scar tissue to the left ventricular area. The number of capillaries was expressed as per $\mathrm{mm}^{2}$ of the infarct border zone. The boxes represent the lower to upper quartile range, the error bars represent the entire range, the horizontal bar represents the median value and dot points represent mean values. 
$-21-$

Figure 6. Detection of grafted SSEA-1-positive progenitors 2 days after epicardial fibrin-patch delivery in a nude rat. In a separate experiment, the fibrin scaffold was intentionally loaded with a high number (two million) of SSEA-1-positive progenitors to optimize visualization of cell patterning shortly (48 hours) after epicardial patch delivery. The cells were embedded into the fibrin patch just after magnetic sorting and grafted in a rnu/rnu nude rat 3 weeks after left coronary ligation. (A) Hematoxylin-Eosin (HE) staining shows a nice incorporation of the fibrin patch harboring the SSEA1-positive progenitors to the surface of the heart. Grafted cells were identified by human specific lamin A/C antibody (B, E, red fluorescence). Many lamin A/C positive cells still expressed the cardiac transcription factor Islet-1 (D, green fluorescence). Panels $\mathrm{C}$ and $\mathrm{F}$ present the merged images $(\mathrm{C}$ : lamin A/C+DAPI-stained blue nuclei; F: combined green [Isl-1]+red [lamin A/C] fluorescence). Arrows indicate grafted cells. Dotted lines indicate the border between the fibrin patch and the heart. Bar: $150 \mu \mathrm{m}(\mathrm{A}) ; 40 \mu \mathrm{m}(\mathrm{B}-\mathrm{C}) ; 20 \mu \mathrm{m}(\mathrm{D}-\mathrm{F})$.

Supplemental Figure 1. Early engraftment of patch-embedded cells. Presence of human cells, staining positively for lamin A/C, 24 hours after the delivery of the cell-loaded fibrin patch onto the epicardium of an infarcted rat heart. Bar: $50 \mu \mathrm{m}$.

\section{Online supplementary material}

Long Term Functional Benefits of Human Embryonic Stem Cell-Derived Cardiac Progenitors Embedded Into a Fibrin Scaffold

Valérie Bellamy ${ }^{\mathrm{a}}$, Valérie Vanneaux ${ }^{\mathrm{b}}$, Alain Bel ${ }^{\mathrm{a}, \mathrm{c}}$, Hany Nemetalla ${ }^{\mathrm{a}, \mathrm{d}}$, Solène Emmanuelle Boitard ${ }^{\mathrm{e}}$, Yohan Farouz ${ }^{\mathrm{a}}$, Pierre Joanne ${ }^{\mathrm{e}}$, Marie-Cécile Perier ${ }^{\mathrm{a}}$, Estelle Robidel ${ }^{\mathrm{a}}$, Chantal Mandet ${ }^{\mathrm{a}}$, Albert Hagège $^{\mathrm{a}, \mathrm{d}}$, Patrick Bruneval ${ }^{\mathrm{a}, \mathrm{f}}$, Jérôme Larghero ${ }^{\mathrm{b}}$, Onnik Agbulut ${ }^{\mathrm{e}^{*}}$, Philippe Menaschée $\mathrm{e}^{\mathrm{a} \mathrm{c}^{*}}$

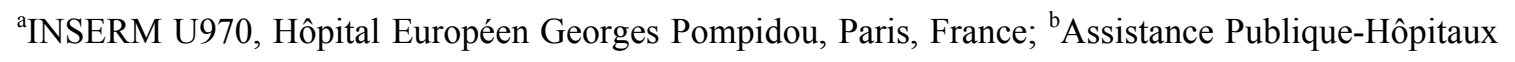
de Paris, Hôpital Saint-Louis, Cell Therapy Unit and Clinical Investigation Center in Biotherapies (CBT501); Inserm UMR1160; Univ Sorbonne Paris Cité, Paris, France; ${ }^{\mathrm{c} A s s i s t a n c e ~ P u b l i q u e-}$ Hôpitaux de Paris, Hôpital Européen Georges Pompidou, Department of Cardiovascular Surgery, 
Paris, France; ${ }^{\mathrm{d} A s s i s t a n c e ~ P u b l i q u e-H o ̂ p i t a u x ~ d e ~ P a r i s, ~ H o ̂ p i t a l ~ E u r o p e ́ e n ~ G e o r g e s ~ P o m p i d o u, ~}$ Department of Cardiology, Paris, France; ' Sorbonne Universités, UPMC Univ Paris 06, IBPS, UMR CNRS 8256, Biological Adaptation and Ageing, Paris-France; ${ }^{\mathrm{f}}$ Assistance Publique-Hôpitaux de Paris, Hôpital Européen Georges Pompidou, Department of Pathology, Paris, France.

Short title. Long-term functional evaluation of cardiac progenitors in ischemic cardiomyopathy

*These authors contributed equally to this work

\section{Corresponding authors}

Philippe Menasché, Department of Cardiovascular Surgery, Hôpital Européen Georges Pompidou, 20, rue Leblanc, 75015 Paris-France. Phone: +33-1-56.09.36.22; philippe.menasche@egp.aphp.fr Onnik Agbulut, UMR CNRS 8256, University Pierre et Marie Curie, 7 quai St-Bernard, 75005 ParisFrance. Phone: +33-1-56.09.36.22; onnik.agbulut@upmc.fr

\section{Supplementary Materials}

\section{Preparation of the SSEA-1 ${ }^{+}$progenitors}

The progenitors were derived from the human embryonic stem cell (ESC) line I6 generously provided by J. Itskovitz and M. Amit (Technion Institute, Haïfa, Israël). Following amplification onto irradiated human fibroblasts in Nutristem тм (Biological Industries, Kibbutz Beit-Haemek, Israel), cells were committed towards a mesodermal-cardiac lineage by reverting the medium to $\alpha$-Minimum Essential Medium Eagle (MEM) solution (Macopharma, Tourcoing, France) enriched with 2\% insulinfree B27 supplement (Invitrogen, Life Technologies, Carlsbad, CA), Bone Morphogenetic Protein (BMP)-2 (Dibodermine alpha, $10 \mathrm{ng} / \mathrm{mL}$, marketed as InductOs ${ }^{\circledR}$ [Wyeth pharmaceuticals, now part of Pfizer, New York, NY]) and a fibroblast growth factor receptor (FGFR)-specific tyrosine kinase inhibitor, SU-5402 (1 $\mu \mathrm{M}$; Merck, Whitehouse Station, NJ). This specification phase lasted for 4 days, at the completion of which cells were immunomagnetically sorted after labeling with a microbead-coupled 
$-23-$

anti-SSEA-1 antibody (Miltenyi, Teterow, Germany). The collected SSEA-1-positive cell yield was checked for its purity (percentage of SSEA-1-positive cells, as assessed by flow cytometry) and a full transcriptomic analysis of the parent undifferentiated I6 ESC, their SSEA-1-positive progeny as well as the SSEA-1-negative fraction was performed using the AffymetrixGeneAtlas ${ }^{\mathrm{TM}}$ system coupled to the new Human Genome U219 array (BIOAlternatives, Gencay, France). Heatmaps representative of this transcriptomic profiling have been previously published ${ }^{24}$ and only the most salient data are presented in Figure $1 \mathrm{~A}$ and $\mathrm{B}$.

\section{Assessment of Left ventricular function}

Left ventricular function was assessed by echocardiography at baseline and every month thereafter until the sacrifice at the 4-month study point as described previously. ${ }^{14}$ Briefly, transthoracic echocardiography (Sequoia 516, Siemens, Seine-St.Denis, France) was performed with a $15 \mathrm{MHz}$ transducer in animals sedated with $2 \%$ isoflurane. Parasternal long and short axis views were obtained with assessment of LV end-diastolic (EDV) and end-systolic (EDS) volumes using the biplane arealength method $\left[(8 / 3 \pi) \times\left(\right.\right.$ LVarea $^{2} /$ LVlength $\left.)\right]$. Ejection fraction was then calculated as (LVEDVLVESV)/(LVESV)x100. All measurements were made in triplicate and averaged by an investigator blinded to the treatment group.

\section{Histological and immunohistochemical analyses}

Four months following the sham or transplantation procedures, rats were euthanized and sacrificed. Explanted hearts were rinsed in PBS, immediately fixed with Shandon Cryomatrix (Thermo Scientific, Illkirch, France) and frozen in $-196{ }^{\circ} \mathrm{C}$ nitrogen. Blocks were stored at $-80{ }^{\circ} \mathrm{C}$ until they were sliced in $7 \mu$ m-cryosections using a cryostat (CM 1850, Leica, Wetzlar, Germany). Vascularisation was assessed in 23 hearts $(n=8,7$ and 8 for sham-operated, control acellular fibrin patches and cell-treated patches, respectively), in both the border zone of the infarct and in remote normal myocardium by immunostaining against rat endothelial cell antigen (RECA, Serotec, Oxford, UK). After exposure to the RECA antibody (diluted 1:30 in PBS-NHS $7 \%$ ) for $30 \mathrm{~min}$, sections were incubated 30 min with a biotin-labelled anti-mouse antibody (Vector Laboratories Inc., Burlingame, CA 94010, USA) and preformed avidin-biotin peroxidase complexes (ABC/PO-solution, Vectastain ABC, Vector Labs 
$-24-$

Inc.), each for $30 \mathrm{~min}$. A freshly prepared peroxidase substrate solution containing 3,5diaminobenzidine (DAB, DAKOCytomation) allowed visualization of RECA by oxidation. After a final wash step, slides were counterstained with hematoxylin and mounted with Faramount ${ }^{\mathrm{TM}}$ (DAKOCytomation each). The blood vessel density was expressed as vessels $/ \mathrm{mm}^{2}$ and 7 sections (in the infarct and border zones) per heart were examined.

Fibrosis was measured by Sirius Red staining in 22 hearts $(n=7,7$ and 8 for sham-operated, control acellular fibrin patches and cell-treated patches, respectively) and, on average, 6 to 10 sections per heart were examined. After fixation of tissue sections with formaldehyde (10 min), slides were rinsed with water before incubation with Sirius Red solution (0.1 \%, 30 min, BDH Chemicals, Poole, UK). Nuclei were counterstained by hematoxyline $(30 \mathrm{sec})$ and slides were mounted with Eukitt (Kindler, Freiburg, Germany). The detection of human cells entailed the use of a monoclonal anti-human lamin A/C antibody (dilution 1/300; Novocastra, A.Menarini, Rungis, France). Furthermore, six hearts were specifically examined for the search of a teratoma. Photographs were taken using a Leica DM2000 microscope (Leica, Wetzlar, Germany) coupled to a Quicam CCD camera (Qimaging Corp., Surrey, BC, Canada). Results were distinguished from autofluorescence by checking all three filters. Data were collected using QCapture software, QCam Driver DLL version 1.73.0 (Qimaging Corp.) and quantified using Metamorph Offline Version 6.3r.2 (Molecular Devices, Sunnyvale, CA).

\section{Relative quantification of gene expression by qPCR}

Total RNA was extracted from heart tissue samples using TRIzol ${ }^{\circ}$ lysis reagent (Life Technologies, Saint-Aubin, France) and TissueLyser II system (Qiagen France SAS, Courtaboeuf, France) following the manufacturers' instructions. Extracted RNA was spectrophotometrically quantified using NanoDrop 2000 (Thermo Fisher Scientific, Saint Herblain, France). From 1000 ng of extracted RNA, the first-strand cDNA was then synthesized using the RevertAid First Strand cDNA Synthesis Kit (Thermo Fisher Scientific) with anchored-oligo(dT) $)_{18}$ primer and according to the manufacturer's instructions using Light Cycler 480 system (Roche Diagnostics, Meylan, France). The reaction was carried out in duplicate for each sample in a $6-\mu 1$ reaction volume containing $3 \mu 1$ of SYBR Green Master Mix, $500 \mathrm{nM}$ each of the forward and reverse primers and $3 \mu 1$ of diluted (1:25) cDNA. The 
$-25-$

thermal profile for SYBR Green qPCR was $95^{\circ} \mathrm{C}$ for $8 \mathrm{~min}$, followed by 40 cycles at $95^{\circ} \mathrm{C}$ for $15 \mathrm{~s}$, $60^{\circ} \mathrm{C}$ for $15 \mathrm{~s}$ and $72^{\circ} \mathrm{C}$ for $30 \mathrm{~s}$. To exclude PCR products amplified from genomic DNA, primers were designed to span one exon-exon junction. Primer sequences used in this study are available on request. The gene expression stability of $B 2 m$, Actb, Hprt1 and Nubp1 were calculated using geNorm software and after analysis only Nubp1 and Actb were used as the references transcripts. Data were collected and analyzed using the LightCycler ${ }^{\circledR} 480$ software release 1.5.0 (Roche).

Fig 1

Figure 1 (Bellamy et al.)
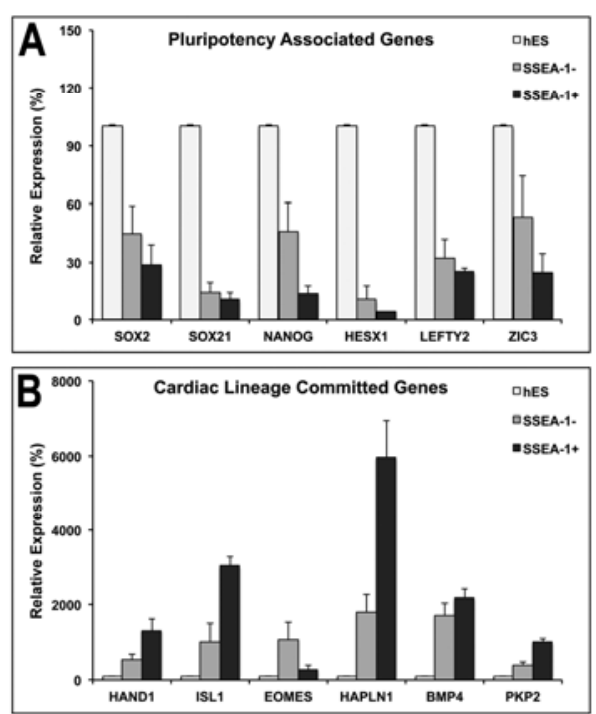
-26 -

Fig 2

Figure 2 (Bellamy et al.)

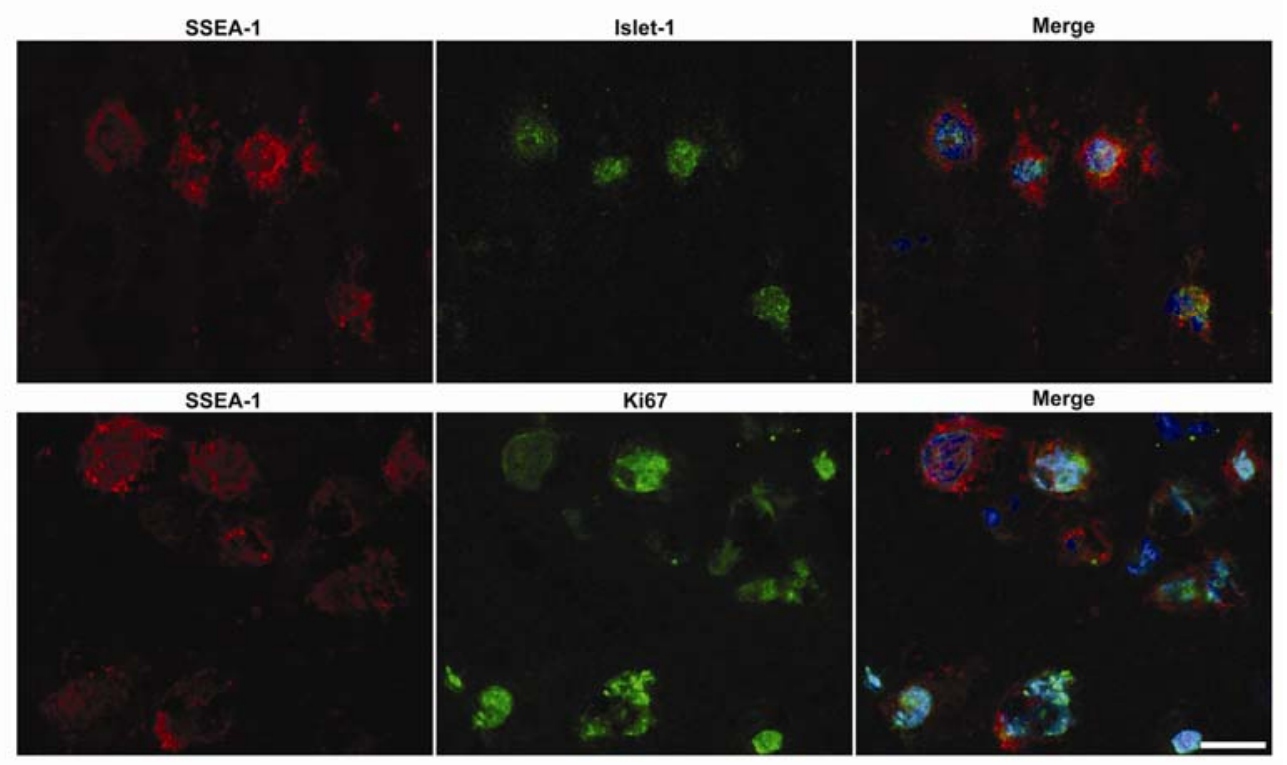


$-27-$

Fig 3

Figure 3 (Bellamy et al.)
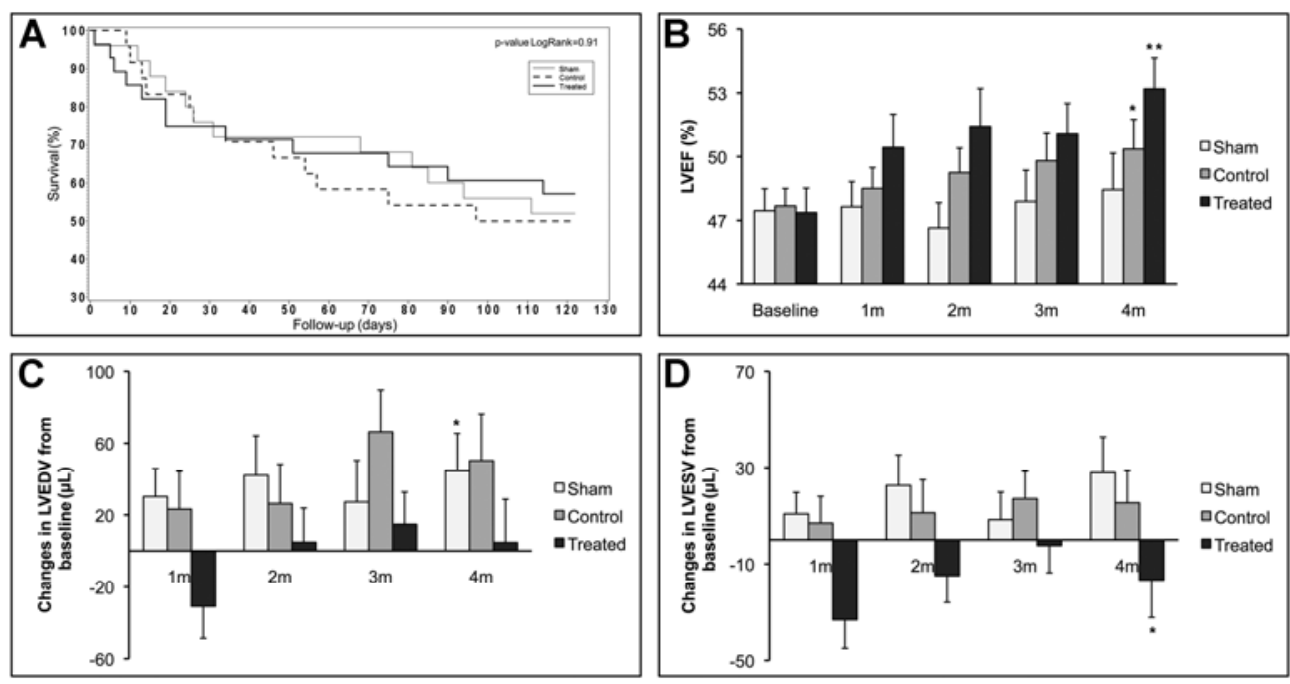
$-28-$

Fig 4

Figure 4 (Bellamy et al.)

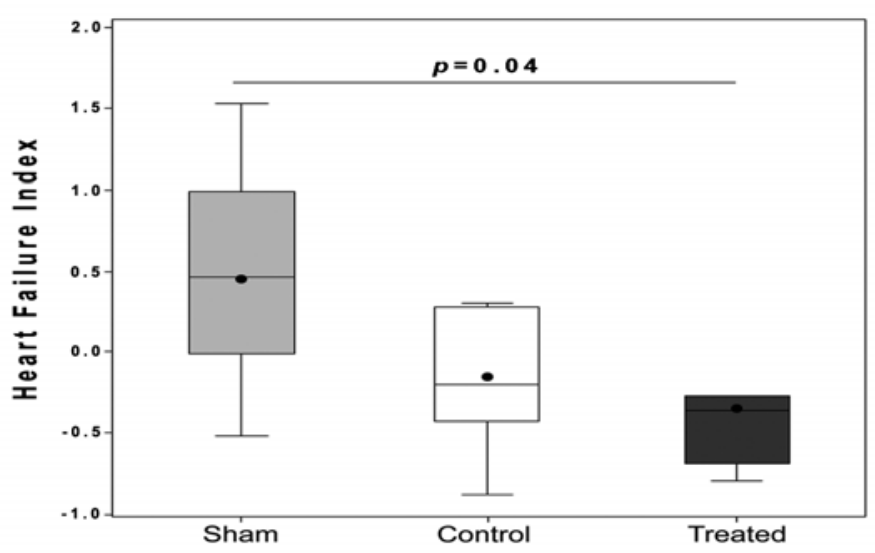


$-29-$

Fig 5

Figure 5 (Bellamy et al.)
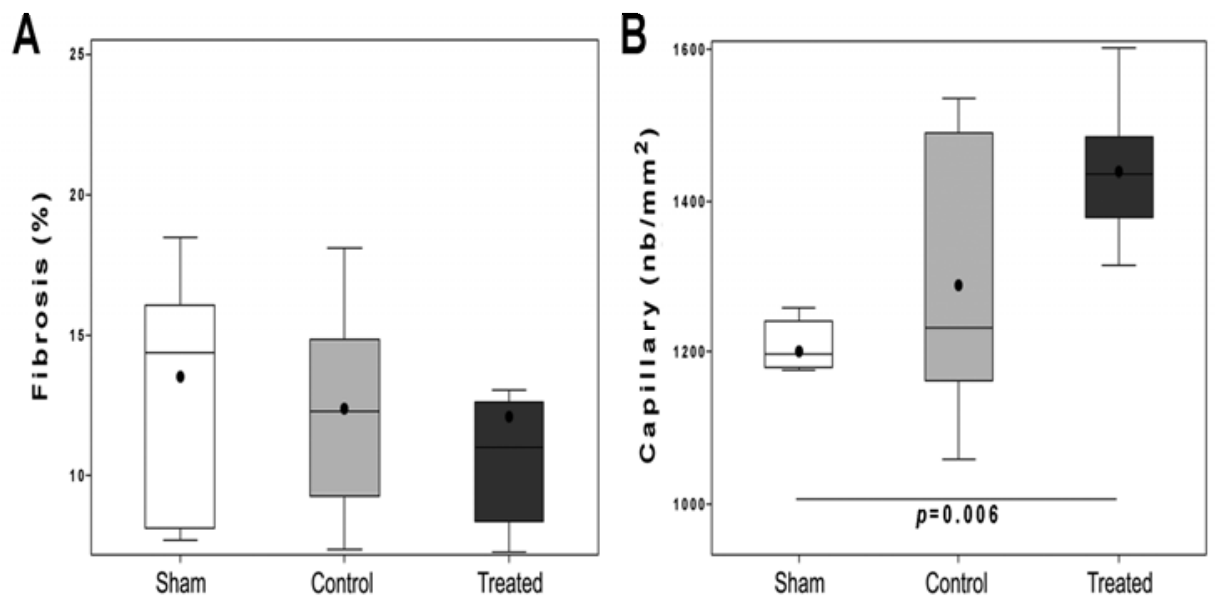
- 30 -

Fig 6

Figure 6 (Bellamy et al.)
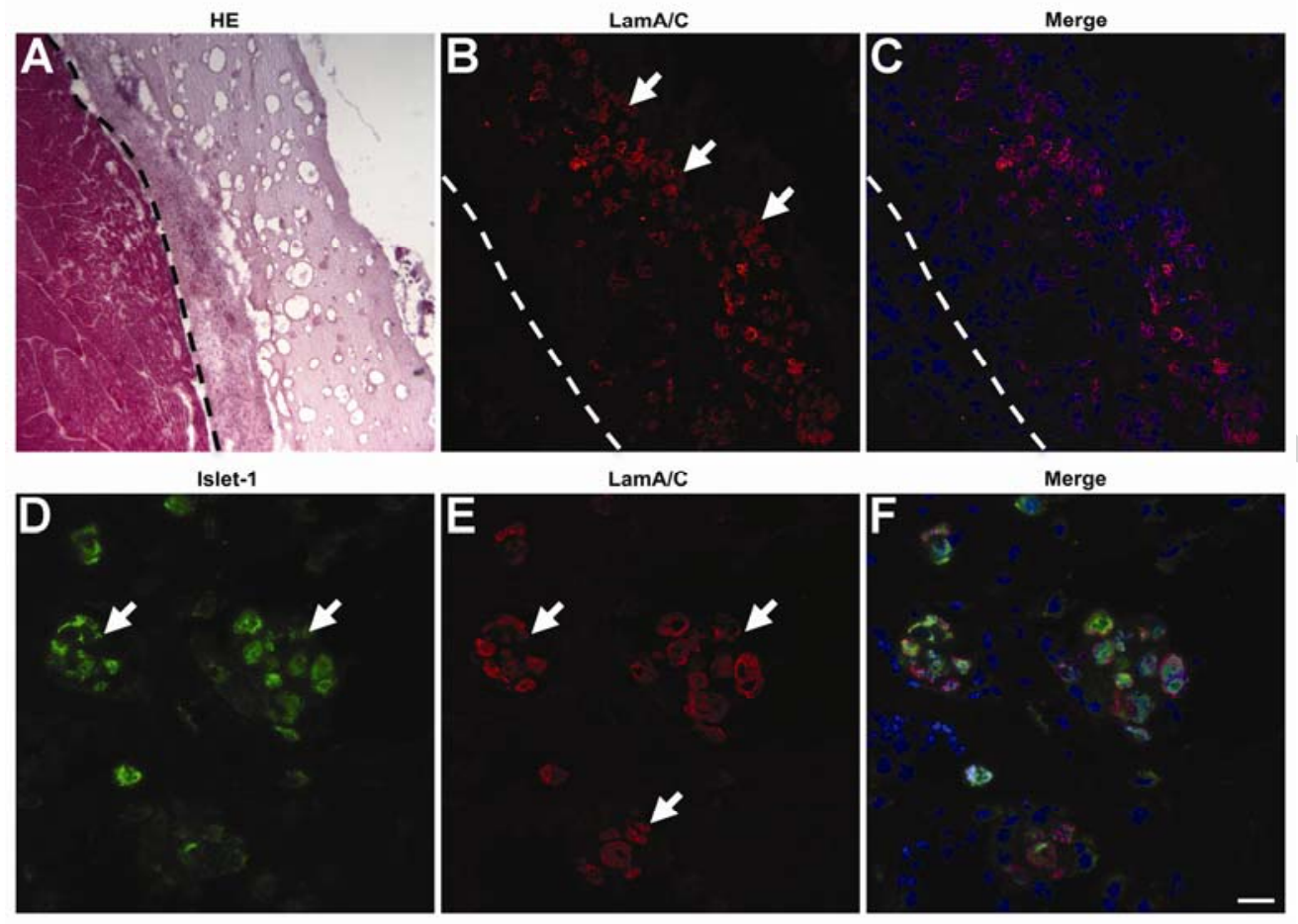